\title{
From transmission to dialogue: Personalised and social knowledge media
}

\author{
Christian Dalsgaard, Department of Information and Media Studies, \\ Aarhus University
}

\begin{abstract}
The purpose of the article is to develop an approach to the use of digital media to support learning. Based on socio-cultural theory, the article develops the concept of knowledge media and argues that personalised and social media can support new ways of learning with media. Personalised and social knowledge media take the individual as the starting point and support the activities of individuals rather than transmitting or broadcasting content. The concept of knowledge media is intended to describe individuals' use of media for learning in both formal and informal situations inside and outside of institutions. How can cultural and educational institutions learn from informal learning situations, how can they utilise digital media to move beyond their physical boundaries and websites, and how can they move from transmission and broadcasting to a dialogical approach?
\end{abstract}

\section{Personalised and social knowledge media - a new perspective on media}

The objective of the article is to introduce the concept of personalised and social knowledge media as a new optic for understanding media used for learning. The term knowledge media is used instead of learning media to underline the point of view of the providers and communicators who aim to provide people with knowledge and support their learning activities. The article looks at institutions with the objective of communicating knowledge. This means that the term covers not only educational institutions, but also cultural institutions. Furthermore, it describes media use in formal as well as informal learning situations. The article focuses on new digital media, specifically the web, which has unique qualities that actualise the conception of knowledge media outlined.

The term knowledge media is not new. The Knowledge Media Institute at the Open University in the UK and the Knowledge Media Research Center in Tübingen, Germany, have used the term for several years. Eisenstadt \& Vincent (1998) define knowledge media as:

"Knowledge Media is about the process of generating, understanding and sharing knowledge using several different media, as well as understanding how the use of different media shape these processes." (Eisenstadt \& Vincent, 1998, p. 4) 
Inspired by this definition, the article develops a socio-cultural understanding of knowledge media. Based on the socio-cultural conception of knowledge I develop a certain understanding of the role that media can play in learning. I will argue that a personalised and social use of media is a unique quality of digital media that can support new ways of learning. Personalised and social media put emphasis on use and dialogue as opposed to a transmission or broadcasting approach to media.

\section{Blurring the boundaries between formal and informal learning}

The concept of knowledge media covers both formal and informal learning situations. An important point is that developments on the web and within digitalisation challenge the distinction between formal and informal learning situations. I deliberately use the terms formal and informal learning situations, because learning processes do not necessarily differ in different learning situations.

Educational institutions are associated with formal learning situations in which learning is formalised and where education is an explicit objective. Informal learning situations are located outside formalized courses and relate to situations in which individuals learn on their own initiative. In addition to the difference between formal and informal, it is also relevant to make a distinction between institutional and non-institutional learning. Learning in cultural institutions such as museums and libraries can be considered informal learning because it does not involve formalised education. However, these situations differ from informal situations in which individuals govern their own activities. The difference is that cultural institutions - specifically museums - organize information and resources in a certain way with certain learning objectives. In that sense, institutional learning situations can relate to institutions such as museums and libraries, which provide knowledge for the public. I will argue that digital media can support a change in the roles of formal and informal as well as institutional and non-institutional learning situations and blur the boundaries between them.

Already, digital media play an increasingly larger role within these situations. Traditionally, education has taken place within educational institutions and has primarily been confined to the physical boundaries of the school campus. E-learning is, however, beginning to play a larger role, but education is still confined to the participants of a course enrolled at educational institutions. In other words, educational institutions are primarily oriented towards classes; i.e. defined groups of pupils or students. Similar to educational institutions, cultural institutions have traditionally provided knowledge to the public within their physical institutions such as libraries and museums. The primary focus of museums is on the collection and storage of materials. As regards communication with the public, the focus of museums is on the development of exhibitions for visitors of the museum. Finally, there is the individual with his or her personal interests and activities. Increasingly, the individual citizen uses the web to find information and resources. According to Bang (2008) the result is a challenge to the sharp boundaries between formal and informal learning situations:

\footnotetext{
"The learning process is becoming increasingly independent of institutions and formal organisations due to the new technologies and as such the scope and potential for selflearning is growing." (Bang, 2008)
} 
In the article I will explore how digital media might be utilised to remove the boundaries between the different learning situations. I will point to new ways in which both educational and cultural institutions can use digital media to move beyond their physical boundaries.

\section{Knowledge media: A socio-cultural concept of media}

Due to the potential breakdown of the boundaries between formal, informal, institutional and non-institutional learning situations, the purpose of the concept of knowledge media is to provide an understanding of media that covers knowledge acquisition in all kinds of situations. It should be possible to use knowledge media in different situations - and not be confined to educational or cultural institutions. The question that knowledge media should answer is: How to organise knowledge for learners in different situations? Broadly speaking, knowledge media are media used for the acquisition of knowledge. Thus, the objective of the concept of knowledge media is to develop an understanding of the role of media in human knowledge acquisition.

Before we can define knowledge media, it is necessary to have an understanding of knowledge and the role of media in the acquisition of knowledge. I will develop a concept of knowledge media from a socio-cultural understanding of learning. The socio-cultural approach rejects the notions that knowledge exists within the mind of the individual and also that knowledge can be externalised in books and other physical objects. Instead, socio-cultural theory argues that knowledge is directly related to human activity and to the social and practical context of humans. This understanding has consequences for an understanding of media and the role that media can play in human knowledge acquisition.

First of all, knowledge acquisition is not considered a passive process, but requires the active engagement of the individual. Acquiring knowledge is not only a matter of active thinking, but is also a matter of performing actions. According to Dewey (1916) knowledge is constructed in relation to goal-directed actions, which have an aim or purpose. It means that knowledge acquisition is a matter of knowledge construction, which requires the individual to be engaged in actions with an aim or purpose. Since knowledge is related to an understanding of the goal of the action, actions must be directed and governed by the individual.

The socio-cultural approach is based on a conception of goal-directed and mediated actions, meaning that actions are mediated by tools (Wertsch 1998). Knowledge is understood as tools used to perform actions. "Tool" is a broad concept, which covers physical objects, linguistic concepts and thoughts (Säljö, 2003). This means that knowledge is not an explicit or tangible phenomenon. Knowledge exists within the active mediation of goal-directed actions, in which a tool is used to perform or helps perform an action. Consequently, knowledge exists neither within the individual nor in the external world; it exists within the mediation. It is not until the individual uses the concept, object, etc. that it is transformed into knowledge. This means that knowledge is defined as media for actions (Dalsgaard, 2007).

Socio-cultural theory places human action within a social practice. First of all, knowledge is related to practice; both the physical practice and the process of practicing (Chaiklin \& Lave, 1996). 
Lave \& Wenger (Lave \& Wenger, 1991; Wenger 1998) have argued that knowledge exists within individuals' participation in communities of practice. Similarly, Suchman's (1987) term situated actions describes actions as being dependent on the context in which they are performed. This means that knowledge is relative to the context and the immediate actions of the individual. Human activity does not take place in isolation. Socio-cultural theory places actions of the individual within a social practice with other individuals and other goals (Leont'ev, 1983). This does not only mean that individuals are related to other individuals within a practice, but also that the meaning of individual actions depends on a collective practice. Knowledge is distributed socially between humans in social structures (Hutchins, 1996; Säljö, 2003; Salomon, 1993). The actions of others are important to the understanding of your own actions. As a consequence, it is important for knowledge acquisition that the individual has an understanding of the collective practice of his/her own actions. In other words, knowledge is relative to the social context of the individual's actions (Dalsgaard, 2007). Social interactions such as communication and participation are important to the knowledge construction process as a means of ensuring insight into the collective practice.

\section{From transmission to use and dialogue}

From a socio-cultural conception of knowledge comes a specific way of understanding the role of media in knowledge construction. Media in themselves are not knowledge media. It is the use of media that make them knowledge media. In that sense, knowledge media is an optic for viewing media, and not a label for media in themselves. Media are potential knowledge media in the sense that they can potentially support the individual's knowledge construction. The socio-cultural approach moves the focus away from the media themselves and towards the actions that the media are used in relation to. As knowledge media, media must support actions of individuals. In other words, the use of media is central, and media only gain meaning in use. In that sense, knowledge media can be defined as media used by individuals to construct knowledge. Media in themselves do not contain specific knowledge.

Following this socio-cultural conception of media, knowledge media should not attempt to organise and convey or transmit knowledge to the individual, but should instead aim at providing a range of possibilities for the individual to perform different activities through the use of media. Development of media for knowledge construction should consider the individual as an active user of, or participant in, the media - not as a (passive) receiver. This is in line with the change in focus that Bardoel \& Lowe (2007) propose. They argue that developments within digital media make it necessary to shift focus from public service broadcasting to public service media. Traditional broadcasting produces completed programmes that are transmitted to receivers. Bardoel \& Lowe (2007) instead argue that, public service broadcasters should "learn to be public service communicators" (Bardoel \& Lowe, 2007, p. 17).

Similarly, a socio-cultural conception of media implies a move away from one-way broadcasting and organisation or structuring of "knowledge" or information. Instead, media as knowledge media should aim at activating individuals, and at creating possibilities for individual and self-governed 
use of media. The purpose of my use of the term knowledge media is to move focus away from a transmission conception of media and towards a discussion of how media can support the activities of users.

The move from a transmission approach also involves dialogue. From a socio-cultural perspective, the most important difference between one-way communication and dialogue is that dialogue engages the individual and enables him/her to participate and influence communication. The individual - not the institution - becomes the starting point for communication. For instance, media used for dialogue provide opportunities to put questions to the individual. Dialogue can involve the individual and the aims, purposes and goals of the individual. In dialogue, communication can become question-based instead of focused on conveying or transmitting knowledge.

This conception of media implies that knowledge media cannot define what knowledge is constructed by the individual or exactly how media are used. Knowledge media can be used in different ways and result in the construction of different knowledge. This presents a challenge for the development of knowledge media: How to develop knowledge media when it is not known how it is to be used and for what purpose? Or how can knowledge media help initiate activities of knowledge construction? The challenge is to initiate and support the goal-directed activities of individuals.

\section{Digital knowledge media}

The socio-cultural conception of media entails the function of the media and the individual's use becoming the starting point for characterisation of media. The focus is not on the specific media described in themselves, but rather the role that they play in the activities of the individual. The same technology can offer a number of functions and, thus, act as different media. Similarly, different technologies can act as the same kind of media.

As a consequence, a categorisation of media based on traditional media concepts such as television, radio, and newspaper is not useful from this perspective. This does not imply that media are made relative. It means that media are not characterised by properties or features, but instead by the human activities they can support. This is highlighted when we look at the web. Since the web can imitate all other kinds of media, the conception of media is challenged (Finnemann, 2005). Since the web enables such a variety of use, it is necessary to have a conceptual frame which does not define the web as one kind of media. The starting point for a discussion of the potential of the web as knowledge media is to direct the focus towards the activities that the web supports. The objective is to discuss the qualities of the web, not from the point of view of technology, but from a user perspective.

All media can be viewed from the optic of knowledge media. However, some media are more suitable as knowledge media than others - depending on the activities they support. Even though television and radio support broadcasting and one-way communication, they can still be used by the individual to construct knowledge. Other media, however, have a larger potential to support individuals' self-governed construction of knowledge. Digital media - primarily the web - bring 
new opportunities for interactivity, user engagement and dialogue, which is interesting to the concept of knowledge media. In that sense, digital media actualise the concept of knowledge media.

\section{Digitalisation: Renewal or more of the same?}

Institutional use of digital media does not mean that the web is replacing educational or cultural institutions. But it is obvious that there is a potential for these institutions to rethink their practice in light of the possibilities provided by the web. This is already happening. Museums and libraries are present on the web, and educational institutions use a variety of digital media. The question is: How can these institutions utilise digital media as knowledge media? I will provide some examples of existing institutional use of digital media. As I will argue, much institutional use of digital media imitates existing practices and does not support the concept of knowledge media. However, the web is used very differently in informal settings, where potential for the use of the web as knowledge media can be identified. I will describe informal use scenarios, which will be used as a starting point for a discussion of institutional knowledge media.

As Bolter \& Grusin (1999) argue through their concept of remediation, any new media must, as a starting point, define itself in relation to existing media, and the dominating form of remediation is the kind that to a large extent aims at imitation of existing practices in the new medium. This is evident in much institutional use of digital media. For example, libraries develop digital libraries, in which materials are organised in the same way as in a physical library; i.e. through the use of metadata and categorisations. The main difference is that access is made easier through search facilities. Similarly, museums make online exhibitions which imitate physical exhibitions, for instance in virtual 3-dimensional rooms (Løssing, 2008). However, museums also extend their exhibitions through the use of interactive elements of digital media (Løssing, 2008).

Finally, educational institutions use new media in a variety of ways. The most significant use of digital media is within e-learning and distance education (Anderson \& Elloumi, 2004; Paulsen, 2003; Bang, 2006). Like cultural institutions, educational institutions to a large extent imitate their existing practice in digital media. A widespread example is learning management systems that are designed to manage courses. Learning management systems support messages from teachers, distribution of course materials, group work, assignments, etc. In other words, imitative remediations of an existing university practice. Another example is podcasting (both audio and video). Many universities podcast audio and video recordings of lectures. Podcasting is an example of an imitative remediation of the lecture. Podcasting is an illustrative example of a typical form of imitative remediation. Bolter \& Grusin (1999) show that, historically, new media have tried to develop a transparent and immediate relation to the "real world". In Denmark there has been a political debate about podcasting all university lectures (http://www.information.dk/139464). This debate is based on the belief that audio or video recordings from lectures create an immediate or transparent access to the real lecture. However, the medium does not disappear, and the podcast will always be a remediation (Bolter \& Grusin, 1999). There is a parallel between educational podcasting and the early days of television, where programmes were often "filmed theatre" or "filmed radio". 
To conclude, an imitative form of remediation is widespread both within educational and cultural institutions. In the examples of learning management systems, digital libraries and online exhibitions, the physical boundaries have been replaced by boundaries of websites or systems. From the point of view of the socio-cultural conception of knowledge media, these kinds of remediation do not utilise the potential of new digital media to support knowledge construction. Furthermore, they preserve the boundaries of institutions.

In contrast to the institutional uses of digital media, several use scenarios in informal settings emphasise dialogue and individuals' use of digital media - not transmission of information. In other words, informal use of digital media outside institutions shows its potential in supporting the conception of knowledge media. Thus, these uses of digital media can inspire institutions to rethink their activities and the way in which learning and knowledge sharing is supported.

Apart from the institutional examples of imitative kinds of remediations, a range of new communication forms have arisen on the web. Informal use of the web has increased dramatically during the last couple of years. Individuals' use of digital media in informal situations develops parallel to institutions. This kind of media use is radically different to that of institutions (Hull, 2003; Willet \& Sefton-Green, 2003; Sørensen et al., 2007), and according to Sørensen (2005) there exists a wide gap between the two. Web-based services such as Myspace, Facebook, YouTube, Twitter, delicious, flickr, Wikipedia and weblogs have experienced a dramatic increase in users. Today, there are more than 100 mio. weblogs worldwide, ${ }^{1}$ in seven years users of Wikipedia have collaboratively written more than 2 mio. articles in the English version of the online encyclopaedia (http://wikipedia.org), Myspace has more than 100 mio. profiles, ${ }^{2}$ and users of the video service YouTube upload more than 50.000 videos a day, while 100 mio. videos are watched every day. ${ }^{3}$

Many of these use situations can be characterised as entertainment. However, the informal use of the web also shows evidence of new ways of learning and knowledge sharing. Educational and cultural institutions might learn from these use scenarios, and from the ways in which individuals use the web for learning in informal situations. There is also the potential for institutions to be a part of the use scenario or culture, which is developing on the web (Hull, 2003). These new kinds of use scenarios prompt a look at digital media from the optic of knowledge media.

In the next sections, I will use examples from informal use of digital media to point towards ways in which institutions can utilise digital media as knowledge media. Based on the socio-cultural conception of knowledge media I will argue that the qualities the web has as knowledge media relate to its personalised and social qualities. The two qualities cannot be separated, but they stress different points in relation to use of the web as knowledge media.

\section{Personalised knowledge media}

When the starting point for developing knowledge media is the activities and context of the individual, it is essential that knowledge media can be personalised in the sense that they enable the individual to use them actively. Personalised knowledge media are opposed to edited broadcasts, which give all users the same access to the media and the materials or information. Instead, per- 
sonalised knowledge media are media that make it possible for users to organize personalised content.

As Lukács (2007) states, digital media have a larger potential than traditional media to develop personalised services. Digital media allow for what Lukács (2007, p. 201) describes as "narrowcasting" and "personalised media services". Personalisation, however, is not only a matter of conveying personalised information, but is also a matter of organising media in a flexible way that can be accessed and organised in different ways. In that way, "narrowcasting" is not an appropriate term. "Differentiation" is also a bit misleading, because it also focuses on the institution's organization of content in relation to different target groups. Instead, personalisation is enabled by providing opportunities for individuals to develop and personalise their own content. Personalisation is carried out by the individual, not the institution. However, the institution's content, information or resources should support personalised use. There are several examples which illustrate the potential of personalised media.

In recent years, personalisation has become a part of discussions within the field of e-learning. The concept of Personal Learning Environments (PLE) has been introduced as an alternative to Learning Management Systems (LMS). Whereas LMS represent a centralized and managed approach to e-learning, the objective of PLE is to enable students to develop their own learning environments from a variety of tools (Wilson et al., 2006; Attwell, 2007).

\section{"The idea of a Personal Learning Environment recognises that learning is continuing and seeks to provide tools to support that learning. It also recognises the role of the individual in organising their own learning. Moreover, the pressures for a PLE are based on the idea that learning will take place in different contexts and situations and will not be provided by a single learning provider. Linked to this is an increasing recognition of the importance of informal learning." (Attwell, 2007)}

A PLE is not a single system, but is rather a collection of personal tools (Attwell, 2007; Dalsgaard, 2006). Personalisation is made possible when users can gather and mix different services, create their unique learning environments and their own ways of using the web. As it is indicated by the concept of PLE (as opposed to LMS), personalisation removes the boundaries between formal and informal learning situations; a personalised use of the web can cover both formal and informal contexts.

On the web, personalisation is supported by many websites and services (Finnemann, 2005). One kind of personalisation is personalised news services (see figure 1). Using a feed reader, people can subscribe to RSS feeds from selected services and in that way organise their own news service. It means that it is possible to develop a news service that consists of sport news from several news services, of news from specific weblogs, of pictures tagged with a specific keyword, etc.

Web sites offer personalised services such as Google's personalised search or Amazon's recommendations of books based on previous purchases. Furthermore, a wide range of web services offer personal tools to support individual use (Dalsgaard, 2006). Examples of personal tools are services for organizing bookmarks, books or literature references. The example in figure 2 is a service 


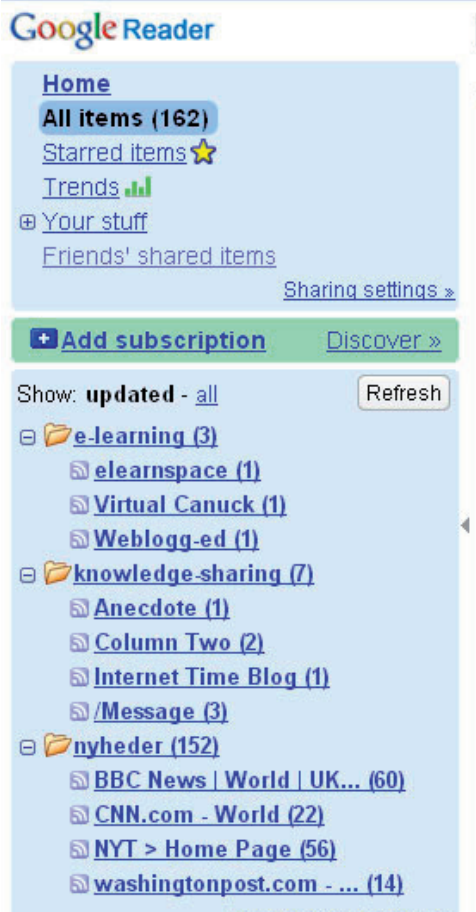

Manage subscriptions *

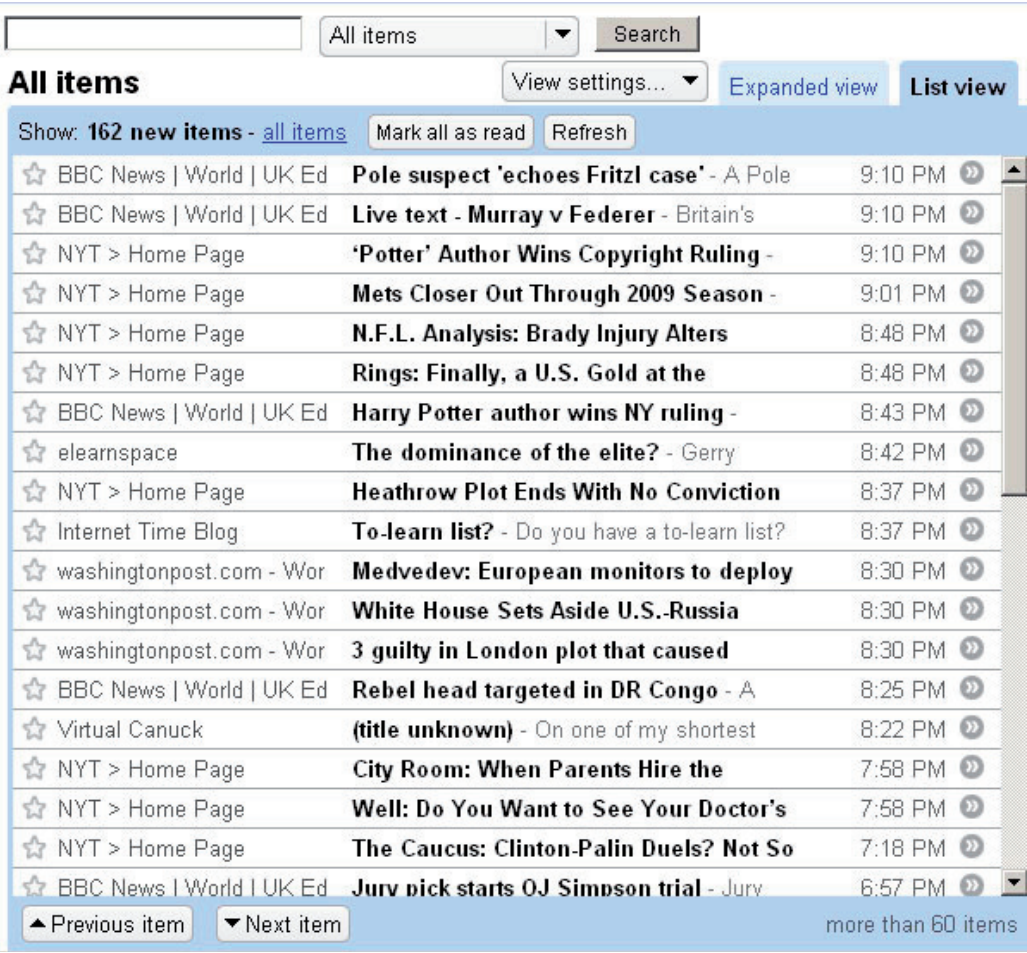

Figure 1. A personalised news service (using Google Reader, www.google.com/reader)

Join llow! What's New? Learn more Help $^{\text {Sign In }}$

delicious Home

\section{cndalsgaard's Bookmarks}

Bookmarks | Network | Tags | Subscriptions

See more bookmarks in Popular or Recent.

$\begin{array}{lr}\text { cndalsgaard Type a tag } & \text { Bookmarks } \\ \begin{array}{l}\text { 12 AUG } 08 \text { Lexipedia - Where words have meaning SAVE } \\ \text { Visual thesaurus. }\end{array} & \text { Sorted by Most Recent } \\ & 10 \\ & \text { sottware dictionary }\end{array}$

10.JuL 08 7th European Conference on eLearning - ECEL-2008 SAvE 17 E-learning conference.

conference e-learning elearning

27 MaY 08 EC-TEL 08: 3rd European Conference on Technology- $\quad 31$

Enhanced Learning | Converging from different

backgrounds SAVE

European Conference on Technology Enhanced Learning.

conference e-learning

07 A.PR 08 Cognitive Edge sAvE

David Snowden

knowledgemanagement knowledgesharing

\begin{tabular}{|l|l|l}
\hline Search these bookmarks & Search & >
\end{tabular}

Save a new bookmark

- Tag options

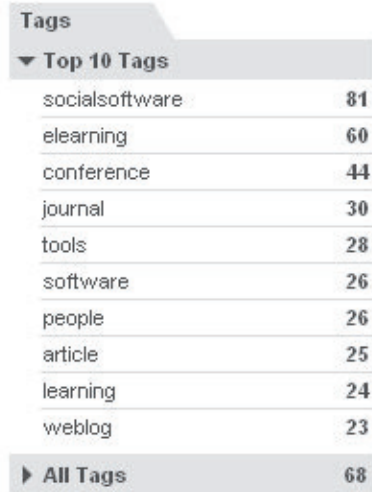

Figure 2. Personal tool for organising web bookmarks (Delicious, http://del.icio.us) 
for personal use and organisation of online bookmarks. Such services also offer recommendations based on personal use.

Finally, the web has the ability to personalise content by providing contextualised information and resources. As stated above, socio-cultural theory relates knowledge to the context of the individual. Contextualisation means that media relate information and resources to the immediate context of the individual. Contextualisation can be achieved by adapting to the physical surroundings and present information in the situation. A simple example of contextual information is signboards placed by tourist attractions. Digital media make it possible to present information beyond the boundaries of physical institutions. Mobile devices and GPS technologies in particular have the potential to support contextualisation (Bang, 2008; Bachmair, 2007). Using digital media, it is possible to present information and content based on a person's physical location, personal profile, and on what the person is searching for in the specific situation (see figure 3). Contextual representation of information and resources differs from - and can supplement - physical collections such as the ones found in museums and libraries. Using contextual knowledge media it is possible to bring information and resources out in new contexts.

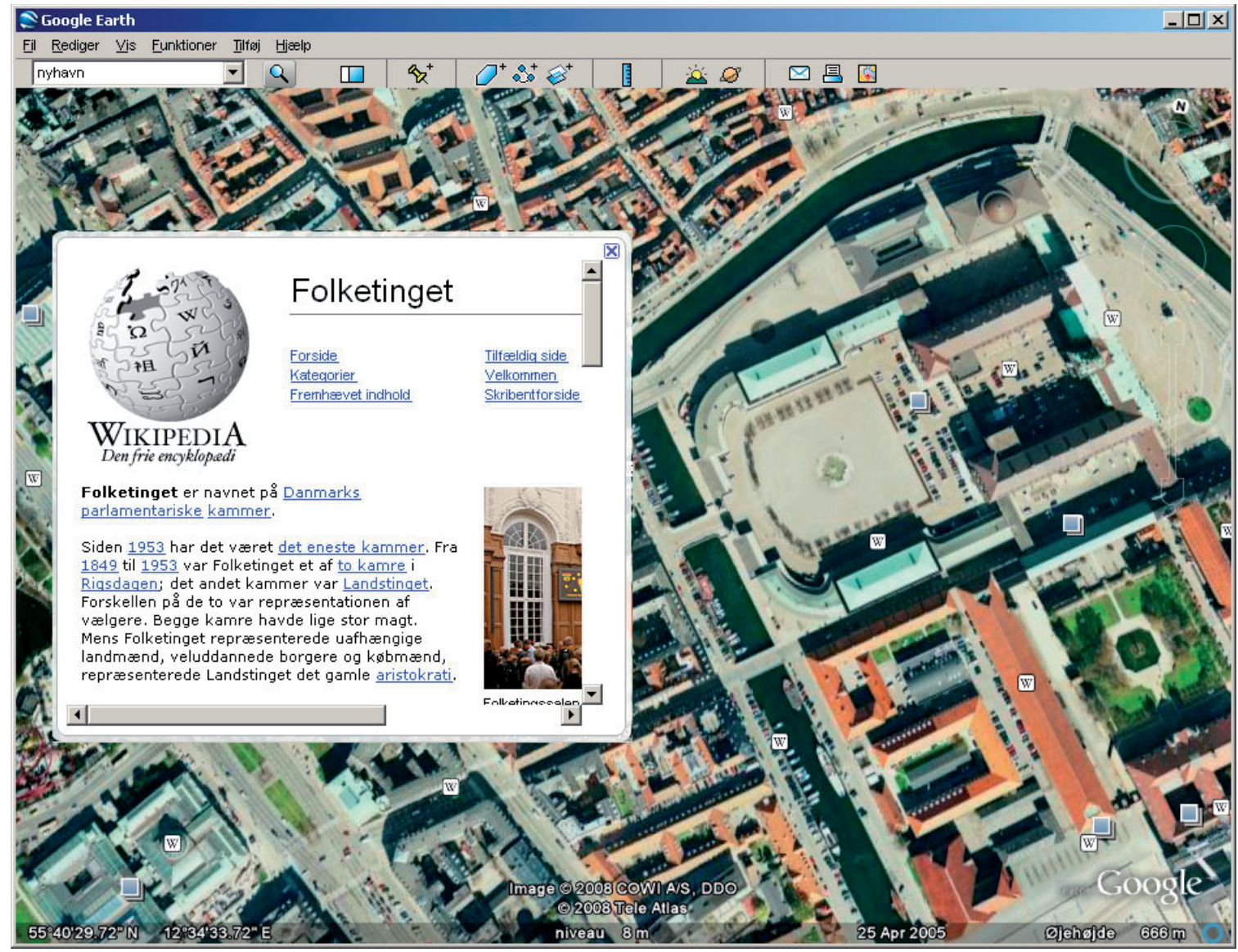

Figure 3. Illustration of the possibilities of contextual representation of information (Google Earth, http://earth.google.com) 


POST A NEW TOPIC WATCH THIS TOPIC Search in: Dubai, United Arab Emirates forums

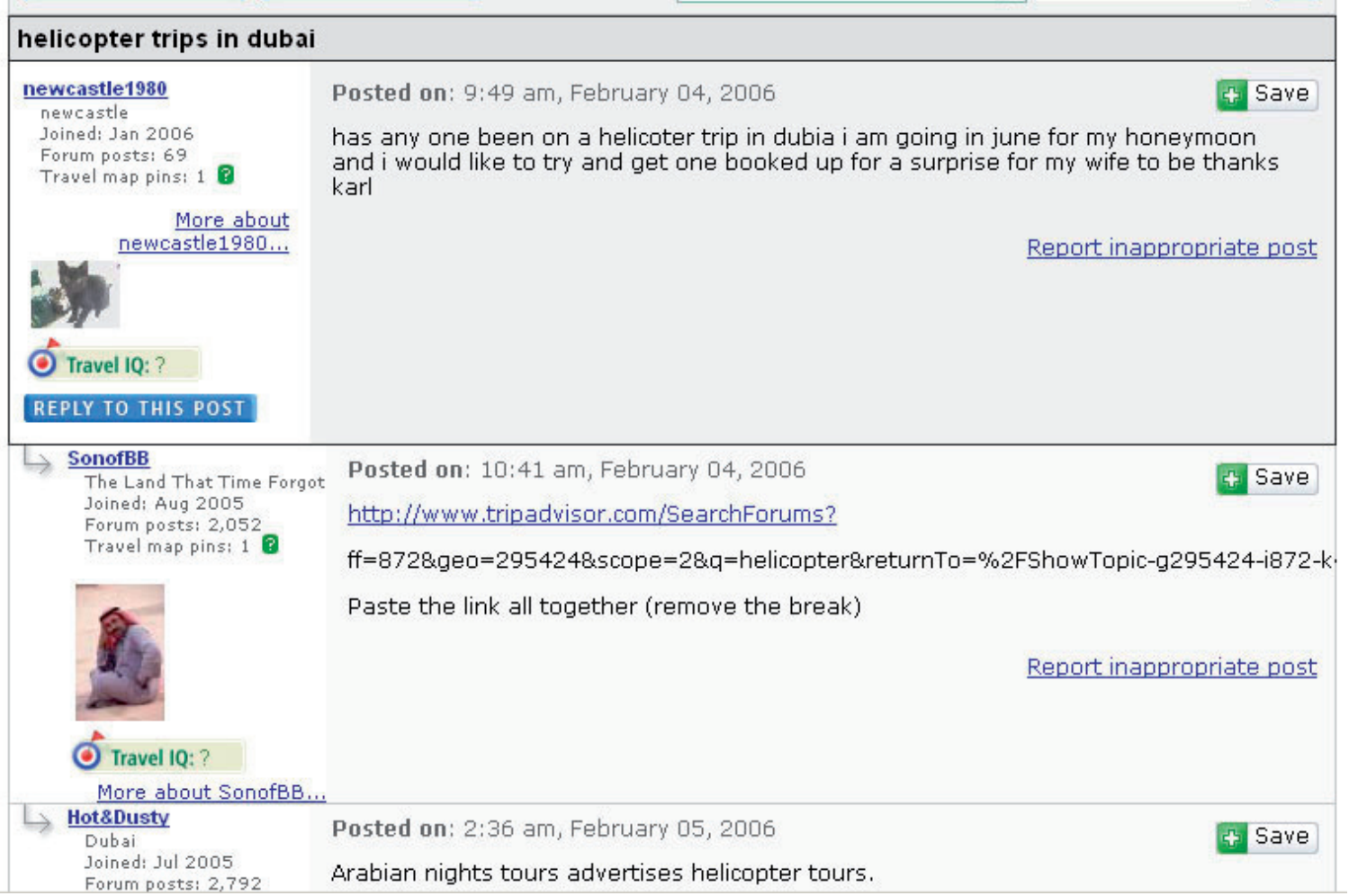

Figure 4. A discussion forum (Tripadvisor, www.tripadvisor.com)

\section{Social knowledge media}

The socio-cultural conception of knowledge construction emphasises the importance of social interaction in the knowledge construction of the individual. This is the argument for the importance of knowledge media having a social nature. Digital media can be utilised as social media, because they enable dialogue, collaboration and social networks.

Social media extend personalisation in the sense that social use of media is also personal and is, thus, a means of personalisation. In contrast to transmission media, social media can be used for two-way communication. It is possible to take questions of the individual as a starting point for dialogue. This is important to the self-governed knowledge construction process. In other words, digital media make it possible for users to participate in discussions and ask questions on basis of their own purposes and situation. An example of social knowledge media is a web-based discussion forum and online communities (see figure 4).

A unique part of the web's potential is the integration of resources and communication; that is, a relation between and simultaneous presence of resources/information and people. Finnemann 


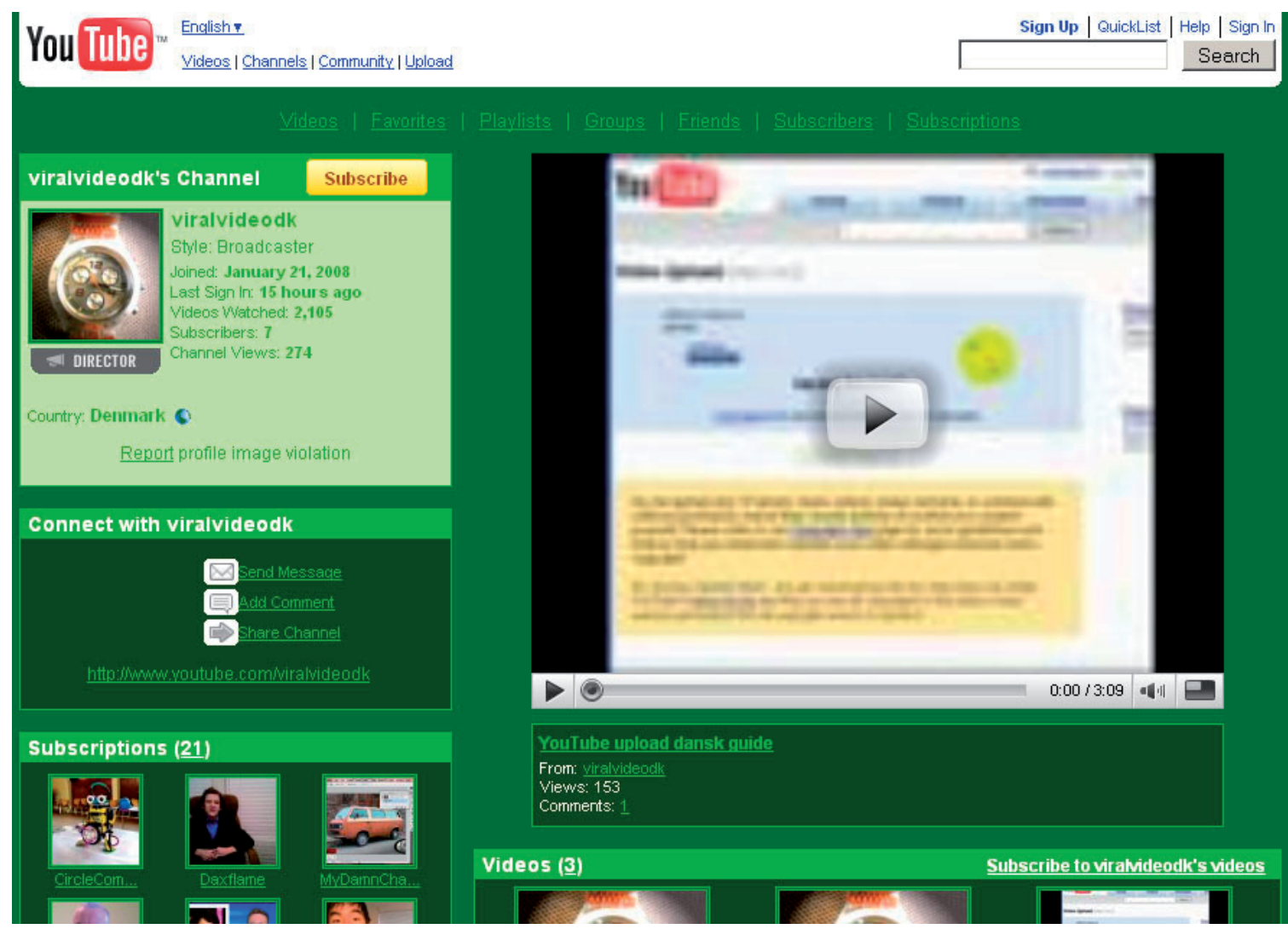

Figure 5. A video on YouTube represented in a channel (http://www.youtube.com/user/viralvideodk)

(2005) states that the most unique and fundamental quality of the web is this connection of archive and high-speed communication.

As social knowledge media, a unique quality of the web is that it can represent information and resources in social networks. Resource-centred social networks such as YouTube, flickr and del.icio. us are social networks build around resources. Person-centred social networks such as Facebook and Myspace have communication as a starting point, but also involve people's displaying and sharing of resources. A precondition for this way of organising information is that the individual person has a representation on the web. For instance, individuals are represented in YouTube by personal channels, and in Facebook by their own profile. As illustrated in figure 5, a resource (in YouTube) is represented in relation to a channel/person, and the same resource can be represented in several channels and thus by different people in several networks.

A central quality of social networks is that they are personal. In that respect, networks differ from discussion forums. Whereas forums are common and shared among a group of participating individuals, a network is unique to the single individual. Networks consist of individual and personal relations.

The integration of communication and resources means that resources are spread in social 
networks. This kind of social knowledge media differs fundamentally from digital libraries, which catalogue and store books and other resources in a similar way to a physical library. In digital libraries, resources are catalogued in one way and in one place using a number of metadata, and the resources are found through search. Placing resources in social networks enables people to find and access them through their personal relations. The social context makes the access to resources personal. In digital libraries everyone has the same access to resources, whereas social networks provide a personalised access. Additionally, digital media make it possible for the same resource to be represented in countless different contexts and social networks.

These examples highlight the potential of personal and social media as knowledge media. In the conclusion, I will point out ways in which institutions can utilise digital knowledge media.

\section{Conclusion}

The article has raised the questions: How can cultural and educational institutions learn from informal learning situations, how can they utilise digital media to move beyond their physical boundaries and websites, and how can they move from transmission and broadcasting to a dialogical approach? Digital media challenge the distinction between formal and informal situations. Institutions can utilise digital media to offer resources and make people available in situations that go beyond formalised educational courses, exhibitions and websites. As Bang (2008) puts it:

"In the future learning environments should bridge the gap between formal and informal learning with a focus on enhancing knowledge acquisition and sharing regardless of whether the provider is an educational institution, museum, gallery, library or mass media supplier." (Bang, 2008)

Following the socio-cultural understanding of personalised and social knowledge media, the starting point for institutional media use is the development of media that support the activities of the individual - whether these activities take place in formal or informal situations, within or outside institutions. The major challenge for institutions is to move beyond their physical boundaries as well as their websites. How can institutions do that?

Libraries could make it possible for users to create personal pages, which, for example, would make it possible to bring recommendations based on individual preferences, similar to Amazon's website. This would provide users with personal access to the resources of the library. However, this use is still confined to the institutional website. In order to bring resources outside the institution, libraries can provide RSS feeds for genres, topics, writers, etc., which would enable users to subscribe to personalised news from the library (cf. figure 1). Furthermore, libraries could enable users to integrate the library's information in personal web pages. Examples of this include LibraryThing (www.librarything.com) and Shelfari (www.shelfari.com), which utilise data from libraries. These services can be used to integrate information on books on, for instance, weblogs and profiles on social networking sites. This means that resources from the library are made visible on personal sites and therefore also in social networks. Thus, there is the potential for libraries to use social networks to spread information on the web. Instead of having to find information and resources in a library or on the library website, individuals find and are made aware of information through 
their social relations. The aim would be to support the development of social networks and communities around the resources of the library, in a similar way to Youtube and flickr (cf. figure 5). This would enable the coupling of resources and communication that was described under social knowledge media.

Similarly, museums can digitalise materials to make them available beyond the museum. Digital remediations cannot replace the physical museum, but can offer an alternative way of accessing the materials. An example is digitalisation of the cultural heritage (Bang, 2007) such as the recent EU initiative i2010: Digital Libraries Initiative ${ }^{4}$, and more specifically the Europeana digital library (www.europeana.eu). Museums can utilise digital media in a similar way to libraries, as discussed above. Furthermore, museums can use digital media to offer information in relation to physical contexts. Using geo-tagging technologies, it is technically possible for a museum to offer context specific information about buildings, specific locations, statues, etc. to a tourist's mobile device (cf. the illustration in figure 3).

Educational institutions can rethink their practice using digital media. Naturally, educational institutions can provide digital resources online. In recent years there has been a movement within Open Educational Resources (OER), which are resources made available for free (OECD, 2007; Gurell, 2008). MIT's OpenCourseWare (http://ocw.mit.edu) was the first example of free educational resources. Another example is Open High School of Utah, which is based solely on OER (Wiley, 2008). Even though OER mark a new role for educational institutions, it is not sufficient to make resources available. In order to make resources available in new contexts outside institutional borders, institutions must first of all develop resources in ways that allow them to be part of other services, communities and networks on the web. The resources should allow for embedding on websites outside the institution, meaning that the resources can be made visible on personal sites and in social networks. An example is educational institutions' use of YouTube (www.youtube. com) and Slideshare (www.slideshare.net), where institutional resources are offered side by side with other resources. For instance, these resources can be integrated into the weblogs of students or teachers from different institutions and nationalities.

Finally, I wish to emphasise the potential of digital media to support institutions' move from transmission and broadcasting to dialogue. Using digital media, institutions can engage in dialogue with their users. First of all, institutions can develop their own forums for discussion and dialogue. For instance, the Danish website videnskab.dk (www.videnskab.dk) invites users to ask questions to researchers. However, this is still within the boundaries of the institution. In order to cross institutional borders, researchers can engage in discussions in web forums outside the institution. The Danish website Kommunikationsforum (www.kommunikationsforum.dk) is an example of a non-institutional forum in which researchers participate in discussions outside their institutions. Researchers can encourage dialogue by participating in online communities, social networking sites and networks of weblogs. For instance, use of personal weblogs is a way to encourage dialogue, and weblogs can also be used to make researchers' resources available in networks outside institutions. 


\section{References}

Anderson, T., \& Elloumi, F. (Eds.) (2004). Theory and Practice of Online Learning. Athabasca University. Retrieved September 29, 2008, from http://cde.athabascau.ca/online_book/

Atwell, G. (2007). Personal Learning Environments - the future of eLearning? eLearning Papers, 2(1). Retrieved September 29, 2008, from http://www.elearningpapers.eu/

Bachmair, B. (2007). M-learning and media use in everyday life: towards a theoretical framework. In Pachler, N. (Ed.). Mobile learning: towards a research agenda. WLE Centre. Retrieved September 29, 2008, from http://www. wlecentre.ac.uk/cms/files/occasionalpapers/mobilelearning_pachler_2007.pdf

Bang, J. (2006). elearning reconsidered. Have e-learning and virtual universities met the expectations? elearningeuropa.info. Retrieved September 29, 2008, from http://www.elearningeuropa.info/directory/index. php? page $=$ doc\&doc_id $=7778 \&$ doclng $=6$

Bang, J. (2007). Biografreklamer som kulturarv. Dansk Reklamefilm. Retrieved September 29, 2008, from http:// www.reklamefilm.statsbiblioteket.dk/biografreklamer_og_kultur_JB.pdf

Bang, J. (2008). Enhancing learning: Potentials of virtual libraries and repositories. EUNIS 2008 Conference Proceedings.

Bolter, J.D., \& Grusin, R. (1999). Remediation: Understanding New Media. The MIT Press.

Chaiklin, S., \& Lave, J. (red.) (1996). Understanding practice. Perspectives on activity and context. Cambridge University Press.

Dalsgaard, C. (2006). Social software: E-learning beyond learning management systems. European Journal of Open, Distance and E-learning, 2006(2). Retrieved September 29, 2008, from http://www.eurodl.org/materials/contrib/2006/Christian_Dalsgaard.htm

Dalsgaard, C. (2007). Åbne læringsressourcer - mod en sociokulturel teori om læringsressourcer [Open-ended learning resources - towards a sociocultural theory of learning resources]. PhD dissertation, Department of Information and Media Studies, Aarhus University. Retrieved September 29, 2008, from http://person.au.dk/ fil/5991913/Phd-afhandling_Dalsgaard.pdf

Eisenstadt, M., \& Vincent, T. (Eds.) (1998). The Knowledge Web. Kogan Page.

Finnemann, N.O. (2005). Internettet i mediehistorisk perspektiv. København: Samfundslitteratur.

Gurell, S. (2008). Open Educational Resources Handbook for Educators Version 1.0. The Center for Open and Sustainable Learning. Retrieved September 29, 2008, from http://www.wikieducator.org/OER_Handbook/educator

Hull, G. (2003). Youth Culture and Digital Media: New Literacies for New Times. Research in the Teaching of English, 38(2).

Hutchins, E. (1996). Learning to Navigate. In Chaiklin, S., \& Lave, J. (Eds.). Understanding practice (pp. 35-63). Cambridge University Press.

Lave, J. \& Wenger, E. (1991). Situated learning: Legitimate peripheral participation. Cambridge University Press.

Løssing, A.S.W. (2008). Danske kunstmuseer på nettet: en kortlægning og diskussion af en kunstmuseal formidlingog udstillingspraksis. PhD dissertation, Institute of Information and Media Studies, University of Aarhus.

Lukács, M. (2007). Education in the Transition to Public Service Media. In Lowe, G. F. \& Bardoel, J. (Eds.). From Public Service Broadcasting to Public Service Media (pp. 199-214). Nordicom.

OECD (2007). Giving Knowledge for Free: The Emergence of Open Educational Resources.

Paulsen, M. F. (2003). Online education. Learning management systems. NKI Forlaget.

Säljö, R. (2003). Læring i praksis: et sociokulturelt perspektiv. København: Hans Reitzels Forlag.

Salomon, G. (1993). Distributed cognitions. Cambridge University Press.

Sørensen, B.H. (2005). ICT and the Gap Between School Pedagogy and Children's Culture. Pedagogy, Culture and Society, 13(1).

Sørensen, B.H., Danielsen, O., \& Nielsen, J. (2007). Children's informal learning in the context of school of knowledge society. Education and Information Technologies, 12(1). 
Suchman, L.A. (1987). Plans and situated actions. Cambridge University Press.

Wenger, E. (1998). Communities of Practice. Cambridge University Press.

Wertsch, J.V. (1998). Mind as Action. New York: Oxford University Press.

Wiley, D. (2008). The Open High School of Utah. Weblog post, May 12, 2008. Retrieved September 29, 2008, from http://opencontent.org/blog/archives/499

Willet, R., \& Sefton-Green, J. (2003). Living and Learning in Chatrooms (or does informal learning have anything to teach us?)....ducation et Sociètiès, 2.

Wilson, S., Liber, O., Johnson, M., Beauvoir, P., Sharples, P., \& Milligan, C. (2006). Personal Learning Environments: Challenging the dominant design of educational systems. ECTEL 2006 Proceedings. Retrieved September 29, 2008, from http://dspace.learningnetworks.org/handle/1820/727

\section{Notes}

1. See http://technorati.com/about/

2. See http://mashable.com/2006/08/09/myspace-hits-100-million-accounts/

3. See http://mashable.com/2006/07/17/youtube-hits-1-million-videos-per-day/

4. See http://ec.europa.eu/information society/activities/digital libraries/index en.htm 